\title{
Alunos silentes online: estudo de caso em uma disciplina do CEFET-MG
}

\author{
Heitor Garcia de Carvalho \\ CEFET - MG
}

\author{
Josefa Aparecida da Silva Souza \\ CEFET - MG
}

\begin{abstract}
Resumo
O artigo apresenta uma análise das interações e silêncio em uma disciplina online do CEFET-MG, ministrada no Facebook, em 2013. Trata-se de estudo de caso, com investigação não participativa, post facto. $\mathrm{Na}$ disciplina foi utilizada dinâmica análoga à sala de aula invertida (flipped classroom).

Palavras Chave: interação, silêncio, flipped classroom
\end{abstract}

\begin{abstract}
This article presents an analysis of the interactions and silence in an online course at CEFET-MG, given via Facebook in 2013. It is a case study, with non-participatory post facto research. The dynamic of the course was analogous to the reversed classroom, or flipped classroom.
\end{abstract}

Keywords: interaction, silence, flipped classroom.

\section{INTRODUÇÃO}

A Educação a Distância (EaD) é regulamentada no Brasil pelo Decreto n ${ }^{\circ} 5.622$ de 19 de dezembro de 2005, definida no artigo $1^{\circ}$ do referido Decreto como modalidade educacional que utiliza as tecnologias de informação e comunicação na mediação didático-pedagógica, com estudantes e professores em lugares ou tempos distintos.

A EaD sempre utilizou as tecnologias que se apresentavam em cada época: as correspondências, rádio, televisão, computador, tecnologias digitais (SANTAELLA, 2013). Importante mencionar que a definição de tecnologia é ampla, nela estando englobados o papel, a caneta, o giz, os meios de transporte, etc. Na leitura de Kenski pode-se entender a abrangência do conceito de tecnologia:

Ao conjunto de conhecimentos e princípios científicos que se aplicam ao planejamento, à construção e à utilização de um equipamento em um determinado tipo de atividade chamamos de tecnologia. (KENSKI, 2007,p.24)

As tecnologias digitais de informação e comunicação (TDIC) têm propiciado à EaD a utilização de ambientes hipermidiáticos como salas de aula virtuais. Nessas salas de aula virtuais, aspecto relevante é que o propósito da $\mathrm{EaD}$ não se circunscreve à simples 
utilização das tecnologias nos processos de ensino e aprendizagem, não se tratando somente de um cenário de incorporação de novos recursos tecnológicos à aprendizagem.

Isto porque essa modalidade de ensino deve utilizar a tecnologia aliada a um projeto pedagógico que vise um ensino de qualidade, possibilite a apropriação do conhecimento e proporcione o alcance de objetivos educacionais valiosos.

Os aspectos relacionados à comunicação dos participantes dos cursos online merecem estudo. A transposição das práticas pedagógicas para os ambientes virtuais tem implicações nas relações dialógicas, fazendo-se necessário investigar se os problemas ocorridos nas salas de aula presenciais, no que tange ao baixo nível e/ou ausência de interação dos participantes, têm também se apresentado nos ambientes virtuais de aprendizagem.

Nesse artigo, apresentam-se os resultados parciais de uma investigação realizada em uma disciplina do Programa de Pós-graduação em Estudos de Linguagem do Centro de Educação Tecnológica de Minas Gerais (CEFET-MG), ministrada no ambiente Facebook, $2^{\circ}$ semestre de 2012.

O objetivo geral da investigação consubstanciou-se em analisar a ocorrência do silêncio virtual na referida disciplina, pretendendo fornecer contribuições para compreensão do silêncio dos alunos nos ambientes virtuais de aprendizagem. Os objetivos específicos foram analisar as interações ocorridas na disciplina em estudo; analisar a estratégia trabalhada pelo Coordenador de Atividades; investigar se há correlação entre o aumento ou diminuição da interação com a estratégia utilizada pelo Coordenador de atividades; apresentar reflexões da pesquisadora, a partir das conclusões da investigação, sobre enfrentamento dos desafios inerentes à ocorrência do silêncio virtual, visando aprimoramento e estímulos aos estudos sobre a Educação a Distância.

\section{INTERAÇÃO}

A importância da interação entre as partes, nos processos de aprendizagem, é reconhecida em pesquisas da lavra de Vigotski (2009), o qual explana que o contato social tem relevância no desenvolvimento do pensamento.

As interações se operam de formas distintas, de acordo com o ambiente de aprendizagem em que são veiculadas. Nos ambientes presenciais de aprendizagem, os participantes, para interagirem, contam com recursos de planos sensoriais diferentes, pois 
há uma proximidade física espacial entre o emissor de mensagens e o destinatário e também uma simultaneidade temporal entre emissão e recepção.

Nos ambientes virtuais de aprendizagem, as interações não contam com os recursos sinestésicos que se apresentam nas interações face a face. Desse modo, em disciplinas não presenciais pode haver um espaço significativo de distância espacial e temporal entre emissão da mensagem e sua recepção e torna-se necessário levar em consideração a interveniência de um sistema ou aparato mediador, neste caso a WEB e seus componentes de hardware e software (AVA/Facebook).

Parreiras (2010) descreve que o meio virtual é um espaço predominante de comunicação textual. Há implicações para os estudantes no que diz respeito ao seu processo de aprendizagem, pois têm que encontrar soluções para compensarem a ausência de interação face a face.

Nas salas de aula virtuais, os problemas relativos às interações entre as partes - que também ocorrem nas salas de aula presenciais - foram mencionados por Gonçalves (2004)

\begin{abstract}
Aspecto difícil de lidar nos grupos virtuais é, sem dúvida, o 'silêncio virtual', cujas origens podem ser as mais variadas. As formações grupais podem propiciar tanto a verbalização quanto o silêncio, o que não é prerrogativa do grupo virtual, uma vez que existe também no presencial. Entretanto, esse problema é mais complexo, pois, se a sua comunicação é pela escrita e esta não existe, resta só o silêncio, não há comunicação (GONÇALVES, 2004, p. 1).
\end{abstract}

Mattar (2012) denomina de vicários os alunos que se "calam" nos ambientes virtuais de aprendizagem. Para o autor, os alunos vicários se posicionam como observadores das discussões e debates, sem participação ativa, mas o autor pontua que essa postura não significa, por si só, que tais alunos terão aprendizagem deficiente, pois eles, em atitude observadora, podem estar a processar e absorver o conteúdo do curso.

É sabido que o docente tem ação importante na mediação do conhecimento. A afirmação vai ao encontro dos estudos de Leão (2014), que acentua a importância do professor como mediador do processo de aprendizagem e descreve que é relevante a existência de conteúdo didático adequado aos perfis diferenciados dos alunos e que propiciem estímulo e comprometimento.

Desse modo, o docente, mediando os recursos didáticos de conteúdo e tecnologia, pode exercer papel relevante para preencher a chamada distância transacional- assim definida por Moore (1993) como o espaço psicológico e de comunicação entre o participante e o docente. 


\section{FLIPPED CLASSROOM}

Uma estratégia apresentada na era digital, que tem merecido atenção dos pesquisadores, é a chamada flipped classroom (VALENTE, 2014). O flipped classroom é uma proposta de modelo a ser utilizado não só nas aulas presenciais, mas também nos ambientes virtuais de aprendizagem e constitui estratégia que intenta "inverter" a sala de aula (Imagem 1), ou seja, apresentar alternativas às salas de aula convencionais, focadas no professor.

Nesse modelo invertido, propõe-se o aluno no centro da aprendizagem, com atividades de caráter mais interativo, tirando proveito dos benefícios que a tecnologia oferece, visando desenvolver aprendizes mais autônomos e participativos. O modelo ajuda os alunos no desenvolvimento de "[...] sentido criativo e a capacidade de trabalhar em equipe de forma cooperativa e colaborativa [...]”. (SILVA, 2015, p.30).

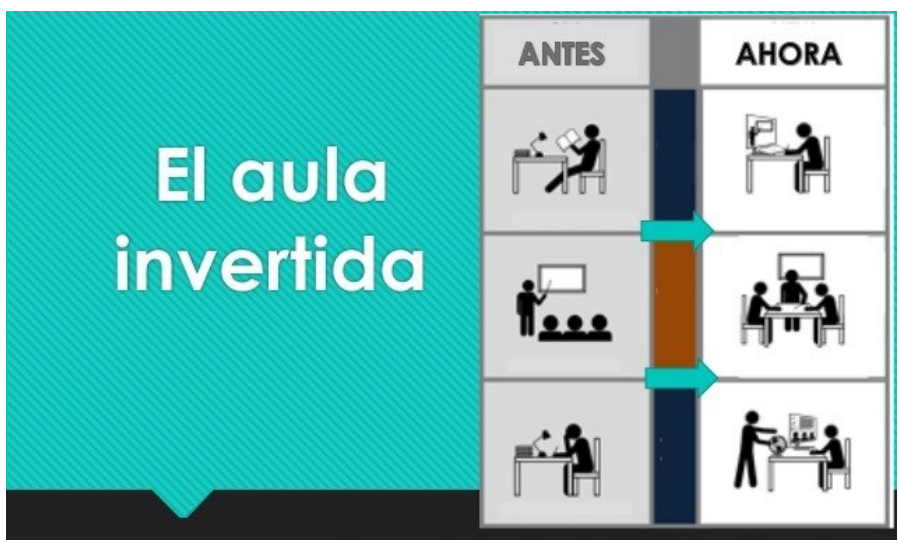

Imagem 1. Fonte $>$ https://academiaintegral.files.wordpress.com/2014/03/aula-invertidasegundo-modelo-academia-integral.png $<$. Acesso em 17/04/2015

Silva (2015) afirma que não há um modelo ideal da metodologia flipped, mas não há divergência acerca do potencial da aula invertida como estimuladora e incentivadora de práticas pedagógicas criativas, com possibilidade de utilização de jogos e vários recursos multimídia. A autora, atenta ao potencial pedagógico da sala de aula invertida, enfatiza que há previsão de que essa dinâmica figure como uma das tendências educativas futuras. 


\section{A INVESTIGAÇÃO}

$\mathrm{Na}$ disciplina online do CEFET-MG, participaram 39 alunos. O curso iniciou-se em dezembro de 2012, com término em abril de 2013 e foi dividido em seis ciclos. Na disciplina atuaram um Coordenador de Atividades e um tutor.

A dinâmica utilizada foi análoga à flipped classroom, com proposição de atividades que possibilitaram aos alunos resolução de projetos e criação de conteúdo, tais como apresentação de resenhas gravadas e apresentadas no ambiente de ensino virtual no formato podcast ${ }^{l}$.

A dinâmica de aula on line utilizada pelo Coordenador de Atividades foi realizada tomando como base as aulas presenciais do Professor Prof. Dr. Heitor Garcia de Carvalho, assim descrita por Leão (2014):

a) o Professor Dr. Heitor Garcia de Carvalho distribui para os discentes um formulário e um texto - que foi selecionado de acordo com o interesse particular do aluno, já apurado previamente, podendo o dito material ser remodelado ao longo do semestre, de acordo com as observações do docente acerca da motivação do aluno;

b) distribuído o material, os discentes têm cerca de 20 minutos para uma leitura dinâmica, de forma a conhecerem a estrutura geral do texto (titulo do texto, nome do autor, palavras-chave e após tal leitura, organizarem uma síntese do material em estudo);

c) de posse da síntese individual, são agrupados em pares, para apresentação do material confeccionado, iniciando a distribuição da aprendizagem com base na colaboração;

d) a seguir, os discentes são reagrupados pelo docente, recebendo então, cada aluno, uma nova numeração, devendo apresentar ao grupo a leitura de seu texto, enquanto os demais integrantes efetuam anotações sobre a apresentação do colega, avaliando-os conforme roteiro apresentado pelo docente, em ficha própria. Um texto diferente para cada aluno objetiva fazer com que os estudantes repassem o conhecimento adquirido, de forma colaborativa;

\footnotetext{
${ }^{1}$ Podcast: produção de áudio que difere da rádio tradicional pela maior maleabilidade de acesso e produção de conteúdo. É uma forma de publicação de programas de áudio na Internet utilizando, na maioria dos casos, o formato de arquivos MP37, que podem ser ouvidos on-line via streaming ou baixados para o computador ou tocador de áudio digital do usuário. $\quad$ Disponível $\mathrm{em}$ : http://cascavel.ufsm.br/revistas/ojs2.2.2/index.php/educacaoespecial/article/view/2028/2438.
} 
e) no terceiro momento, troca-se novamente os grupos, de acordo com o número recebido por cada aluno. A nova formação do grupo permite novas interações, e os estudantes vão completando as fichas de avaliação, que exigem como última atividade, uma dissertação sobre alguns dos textos lidos;

f) desfazem-se os grupos e cada aluno é chamado a apresentar sinteticamente, uma opinião sobre a aula, para reflexão sobre o processo de aprendizagem.

Utilizando metodologia on line análoga à acima citada, o Coordenador das atividades, utilizou a seguinte dinâmica na disciplina de "Práticas de letramento: identidade e formação do professor", segundo Leão (2014):

a) cada ciclo da disciplina iniciou-se com a indicação de uma bibliografia básica a todos os participantes, dividindo-os em grupo para que cada um redigisse uma resenha individual. Em tópico criado na página Facebook todos debateram sobre o texto base, para acrescer novos saberes e complementarem as resenhas já confeccionadas individualmente;

b) foi dada aos participantes a tarefa de criarem, individualmente, um vídeo ou podcast narrando o que foi abordado pelos colegas, com duração de 1 a 2 minutos, bem como assistirem/ouvirem todas as resenhas postadas, para revisarem e acrescerem conteúdo ao material individual;

c) monitor - escolhido previamente, propôs um debate nominado "Fórum de Discussão", para trabalho conjunto, independente do grupo que os discentes estavam inseridos;

d) cada aluno recebeu um texto complementar, para elaborar a segunda parte de sua resenha, com posterior encaminhamento ao monitor e postagem de contribuições no tópico de seu grupo, com referência aos textos lidos;

e) o monitor compartilhou, no Facebook, um texto resultante das resenhas individuais, oportunidade em que o grupo pode fazer os ajustes, para deixar o texto apto a ser publicado na página do grupo, finalizando assim a etapa;

f) a partir das contribuições dos demais membros do grupo, os participantes aprimoraram suas resenhas e editaram um podcast, com extensão de 1 a 2 minutos, possuindo a incumbência de assistirem aos podcasts dos demais colegas. 
Os feedbacks dos alunos possibilitaram ao Prof. Dr. Vicente Aguimar Parreiras modificações para otimizar a dinâmica oferecida.

A hipótese de investigação cinge-se na suposição de que a dinâmica utilizada pode propiciar aumento das interações.

Tratou-se de uma pesquisa predominantemente qualitativa, que envolveu um estudo de vários significados, motivos, atitudes (MINAYO, 2001). Os dados quantitativos não foram desprezados, procedimento que não possui óbice por parte de tais autores como é apontado por Oliveira (2010).

Os dados foram coletados no ambiente do curso, post facto, analisando-se os registros escritos pelos participantes e que foram conservados nos "logs" do sistema pelo Facebook.

Na pesquisa foi realizado um recorte, englobando os seguintes questionamentos: na disciplina em análise foi observada baixa interação/e/ou silêncio dos participantes? Que tipos de interação foram observados? Qual(is) achado(s) pode(m) ter relevância para o favorecimento ou decréscimos das interações?

\section{RESULTADOS}

No Ciclo 1 (02/12/2012 A 23/12/2012), verifica-se, a partir dos números inseridos no Gráfico 1, que os alunos A2, A4, A5, A6, A7, A9, A10, A12, A13, A14, A15, A18. A19, A22, A23, A24, A25, A26, A30, A31, A34, A36, A38, A39 não efetuaram nenhuma postagem de mensagens. Desse modo, dos 39 participantes inscritos, apenas 15 postaram mensagens no ciclo em análise, ou seja, 38,46\% interagiram através de postagens de mensagens.

Na prorrogação do Ciclo 1 (24/12/12 a 02/02/13), verifica-se, a partir dos números inseridos no Gráfico 2, que os alunos, A3, A4, A9, A10, A12, A13, A14, A22, A23, A25, $\mathrm{A} 26, \mathrm{~A} 27, \mathrm{~A} 29, \mathrm{~A} 30, \mathrm{~A} 31, \mathrm{~A} 32, \mathrm{~A} 33, \mathrm{~A} 34, \mathrm{~A} 35, \mathrm{~A} 36, \mathrm{~A} 38$ e A39 não postaram mensagens. Desse modo, dos 39 participantes, apenas 17 postaram mensagens no curso em análise, ou seja, 43,59\% interagiram. 
Gráfico 1- Interações (ciclo 1)

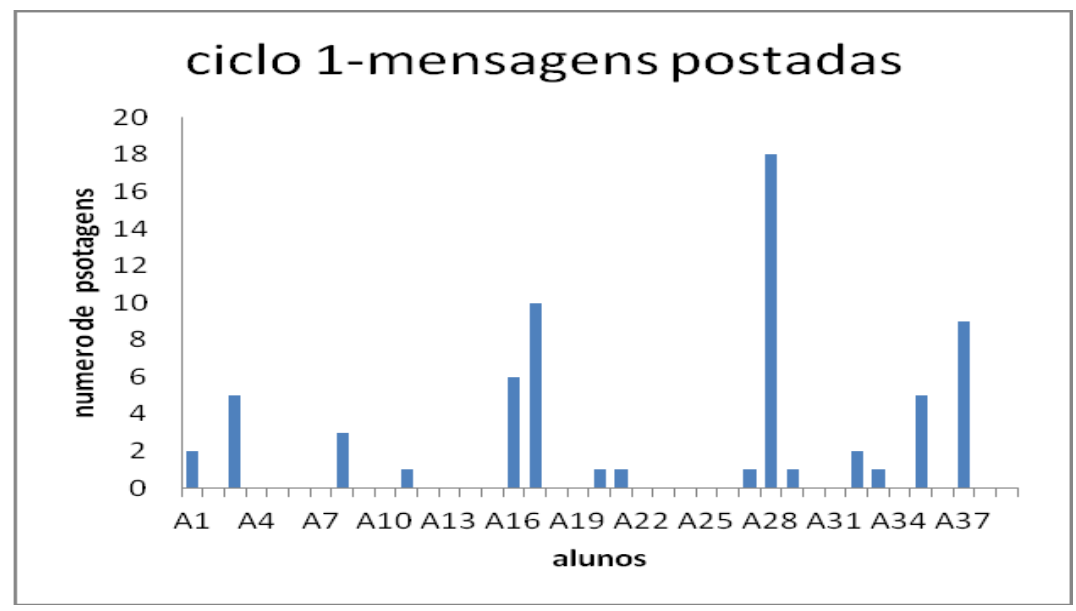

Fonte: a autora

Gráfico 2- Interações (prorrogação do ciclo 1)

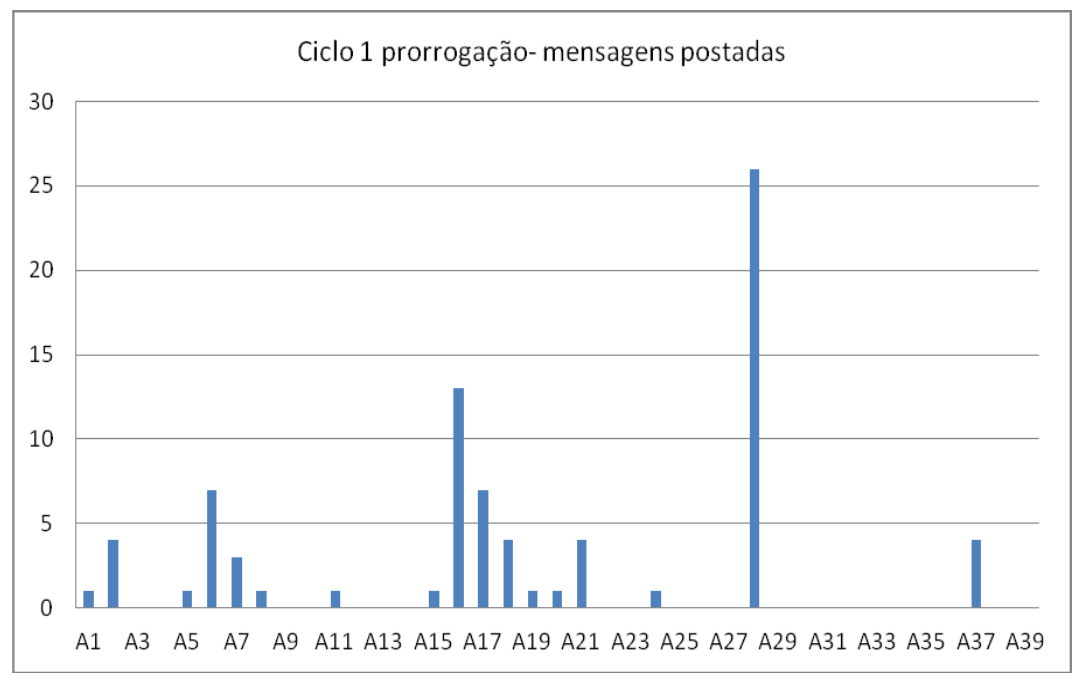

Fonte: a autora

As interações dos participantes foram assim categorizadas:

1- Considerações do participante endereçadas ao grupo como um todo

2- Considerações do participante endereçadas a um participante específico

3- Considerações do aluno endereçadas ao tutor

4- Considerações do participante endereçadas ao Coordenador de atividades

5- Perguntas retóricas (convite à interação)

6- Perguntas diretas ao tutor 
7- Perguntas diretas ao Coordenador de atividades

8- Respostas a questionamento do tutor

9- Respostas ao questionamento do Coordenador de Atividades

10- Resposta a questionamento indiretos dos colegas

11-Conversa social do participante com um colega

12-Conversa social do participante com o Coordenador de Atividades

13-Conversa social do participante com o tutor

14- Conversa social do participante com o grupo como um todo

Interações categorizadas Ciclo 1

\begin{tabular}{|c|c|c|c|}
\hline ALUNO & $\begin{array}{l}\text { QUANTIDADE } \\
\text { INTERAÇOES }\end{array}$ & $\begin{array}{l}\text { CATEGORIA } \\
\text { INTERAÇÕES }\end{array}$ & DATA \\
\hline $\mathrm{A} 1$ & 2 & 2 & $13 / 12 / 2012$ \\
\hline \multirow[t]{2}{*}{ A3 } & 1 & 1 & $16 / 12 / 2012$ \\
\hline & 2 & 2 & $16 / 12 / 2012$ \\
\hline \multirow[t]{3}{*}{ A8 } & 1 & 2 & $12 / 12 / 2012$ \\
\hline & 1 & 11 & $12 / 12 / 2012$ \\
\hline & 1 & 1 & $22 / 12 / 2012$ \\
\hline A11 & 1 & 1 & $23 / 12 / 2012$ \\
\hline \multirow[t]{6}{*}{ A16 } & 1 & 1 & $14 / 12 / 2012$ \\
\hline & 1 & 1 & $15 / 12 / 2012$ \\
\hline & 1 & 4 & $17 / 12 / 2012$ \\
\hline & 2 & 2 & $17 / 12 / 2012$ \\
\hline & 1 & 6 & $18 / 12 / 2012$ \\
\hline & 1 & 8 & $19 / 12 / 2012$ \\
\hline \multirow[t]{8}{*}{ A17 } & 2 & 11 & $12 / 12 / 2012$ \\
\hline & 1 & 13 & $12 / 12 / 2012$ \\
\hline & 1 & 11 & $17 / 12 / 2012$ \\
\hline & 3 & 2 & $12 / 12 / 2012$ \\
\hline & 1 & 13 & $14 / 12 / 2012$ \\
\hline & 1 & 1 & $20 / 12 / 2012$ \\
\hline & 1 & 7 & $17 / 12 / 2012$ \\
\hline & 1 & 11 & $23 / 12 / 2012$ \\
\hline A20 & 1 & 1 & $19 / 12 / 2012$ \\
\hline A21 & 1 & 8 & $18 / 12 / 2012$ \\
\hline A27 & 1 & 1 & $18 / 12 / 2012$ \\
\hline \multirow[t]{19}{*}{ A28 } & 1 & 1 & $12 / 12 / 2012$ \\
\hline & 1 & 11 & $12 / 12 / 2012$ \\
\hline & 1 & 11 & $12 / 12 / 2012$ \\
\hline & 1 & 14 & $12 / 12 / 2012$ \\
\hline & 1 & 14 & $12 / 12 / 2012$ \\
\hline & 1 & 11 & $12 / 12 / 2012$ \\
\hline & 1 & 6 & $12 / 12 / 2012$ \\
\hline & 1 & 8 & $12 / 12 / 2012$ \\
\hline & 1 & 12 & $12 / 12 / 2012$ \\
\hline & 1 & 12 & $12 / 12 / 2012$ \\
\hline & 1 & 6 & $12 / 12 / 2012$ \\
\hline & 1 & 11 & $12 / 12 / 2012$ \\
\hline & 1 & 5 & $13 / 12 / 2012$ \\
\hline & 1 & 6 & $13 / 12 / 2012$ \\
\hline & 1 & 1 & $15 / 12 / 2012$ \\
\hline & 1 & 2 & $16 / 12 / 2012$ \\
\hline & 1 & 2 & $18 / 12 / 2012$ \\
\hline & 1 & 10 & $20 / 12 / 2012$ \\
\hline & 1 & 11 & $23 / 12 / 2012$ \\
\hline
\end{tabular}




\begin{tabular}{c|c|c|c}
\hline A29 & 1 & 1 & $23 / 12 / 2012$ \\
\hline A32 & 1 & 13 & $12 / 12 / 2012$ \\
\hline & 1 & 14 & $13 / 12 / 2012$ \\
\hline A33 & 1 & 1 & $12 / / 12 / 2012$ \\
\hline A35 & 2 & 1 & $15 / 12 / 2012$ \\
\hline & 1 & 9 & $14 / 12 / 2012$ \\
\hline & 1 & 1 & $14 / 12 / 2012$ \\
\hline & 1 & 1 & $15 / 12 / 2012$ \\
\hline & 1 & 3 & $15 / 12 / 2012$ \\
\hline A37 & 1 & 11 & $13 / 12 / 2012$ \\
\hline & 2 & 13 & $13 / 12 / 2012$ \\
\hline & 3 & 1 & $13 / 12 / 2012$ \\
\hline & 1 & 13 & $14 / 12 / 2012$ \\
\hline & 2 & 13 & $15 / 12 / 2012$ \\
\hline & 1 & 3 & $14 / 12 / 2012$ \\
\hline & & &
\end{tabular}

Fonte: a autora

Pela definição operacional de silêncio virtual adotada (não aposição de mensagens no ambiente hipermidiático de aprendizagem) a maioria dos participantes manteve-se em silêncio virtual durante todo o período do $1^{\mathrm{o}}$ ciclo. Mesmo os participantes que apuseram mensagens no ambiente virtual, fizeram poucas vezes essa ação.

\section{DISCUSSÃO/CONCLUSÃO}

Verificou-se a existência de participantes "silentes online" nos dois ciclos examinados (no ciclo 1 os alunos A2, A4, A5, A6, A7, A9, A10, A12, A13, A14, A15, A18, A19, A22, A23, A24, A25, A26, A30, A31, A34, A36, A38, A39 não efetuaram nenhuma postagem de mensagens e na prorrogação do ciclo 1 os alunos A3, A4, A9, A10, A12, A13, A14, A22, A23, A25, A26, A27, A29, A30, A31, A32, A33, A34, A35, A36, A38 e A39 não postaram mensagens).

Usando a nomenclatura de Mattar (2012), percebe-se então que houve participantes com interação vicária, ou seja, participantes que permaneceram calados nos ambientes virtuais de aprendizagem.

Entretanto a falta de aposição de mensagens no ambiente virtual não pode, por si só, denotar letargia interacional. Os participantes podem necessitar de um período de tempo para leitura e apropriação do conteúdo exposto antes de terem condições de elaborar uma mensagem própria. Podem também efetuar interações através de troca de mensagens fora do ambiente virtual de aprendizagem e que não poderiam ser detectadas usando-se apenas os "logs" do Facebook.

Tais interações extras foram notadas: o participante A6 apôs mensagem no ambiente de estudos, relatando que enviou email para o participante A28: 


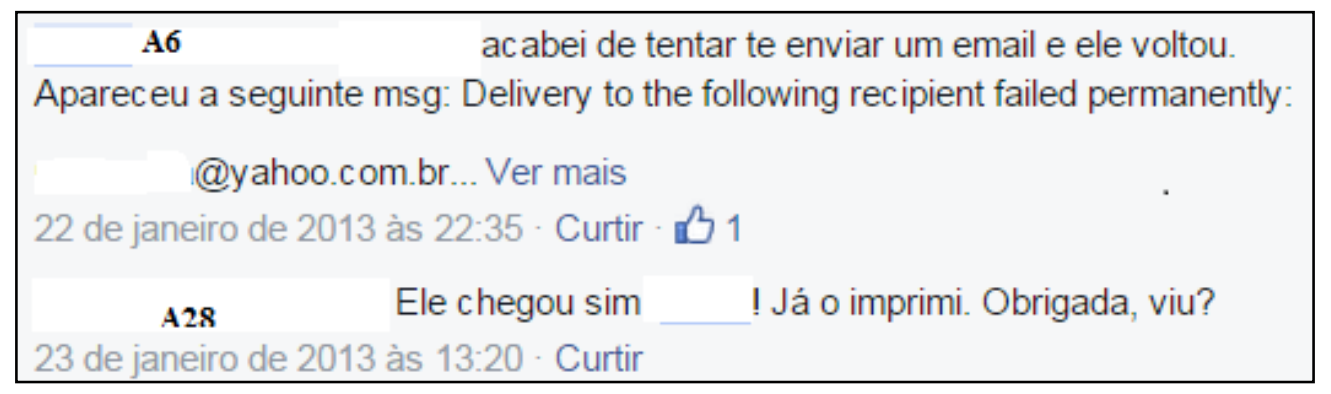

Houve um acréscimo nas interações postadas nos ciclos estudados, com consequente diminuição do "silêncio virtual": as postagens aumentaram de 38,46\% para $43,59 \%$, conforme demonstram os gráficos 1 e 2 .

As análises iniciais demonstraram que no Ciclo 1 as interações dos participantes foram relativamente poucas, sendo que $38,36 \%$ postaram mensagens no ambiente hipermidiático e $61,54 \%$ não postaram nenhuma mensagem.

$\mathrm{O}$ primeiro ímpeto que se tem, diante dos resultados apresentados, é atribuir à expressão silêncio virtual, simplesmente o significado operacional de:

Silêncio virtual $=$ ausência de escrita no ambiente virtual

Entretanto, existem variáveis que devem ser mencionadas e que podem ter influência no estudo do silêncio dos participantes. Moran (2012, p. 50) descreve que o ritmo dos discentes, no virtual ou no presencial, sofre interferência de vários fatores:

[...] alguns alunos se comunicam bem no virtual, outros não. Alguns são rápidos na escrita e no raciocínio, outros não. Alguns tentam monopolizar as falas (como no presencial) outros ficam só como observadores. O ritmo do presencial-virtual depende de muitos fatores.

A conceituação simplista de silêncio virtual acima exposta ceifa vários dos atributos maiores da EaD, quais sejam: caráter democrático manifesto na flexibilidade de escolha de horários para leitura e horários para participação no ambiente - quando não pactuados, nas regras do curso, tais como horários de participação.

Não se pode olvidar também que cada participante, dadas as suas características pessoais de aprendizagem e seu contexto de vida (horários de trabalho, vida familiar, etc.) necessita de períodos para contato com o material didático (períodos de leitura), podendo assim estar em silêncio no que tange à interação social (sem interação Participante $\mathrm{X}$ Coordenador de Atividades e participante e seus pares), mas em trabalho no que tange ao contato com o material didático (interação participante material didático). 
Uma questão muito relevante surgida no decorrer das análises acima mencionadas foi a dificuldade de conceituação de "silêncio virtual". Em situação presencial as interações entre participantes são integradas também por linguagem não verbal, como implicado na expressão "o corpo fala". Um gesto pode significar, por exemplo, "sim", como um sinal com as mãos ou a cabeça. A simples expressão do rosto pode indicar concordância, discordância, enfado, entusiasmo, distração e muitas outras mensagens explícitas ou subliminares. Quando há intervenção de um sistema de ambiente virtual de aprendizagem (AVA) muitas dessas possibilidades mencionadas são inibidas ou se deslocam em relação ao sincronismo. Um conferencista pode captar tais contramensagens da reação do auditório e introduzir explicações adicionais, mudar o curso da sua fala, gesticular ou mudar suas mensagens corporais. Um participante de um curso online, por exemplo, assistindo um vídeo dois dias depois de emitido terá reações diferentes de quem o faz simultaneamente em webcam. Também o ambiente não terá, provavelmente, a companhia física e próxima de outros co-participantes como ocorre no ensino presencial. Talvez entre a emissão original do vídeo e o momento em que um participante o está assistindo cheguem mensagens e/ou aconteçam fatos que induzirão a interpretações diferentes sobre aquele conteúdo. Por exemplo, um participante que tenha assistido antes pode ter enviado a todos um comentário que pode ser favorável ou desfavorável. Certamente assistindo tal vídeo e/ou mensagem escrita ou em podcast depois desta outra intervenção, já haverá predisposição favorável ou desfavorável ao conteúdo.

O participante do curso online, em geral, pode ser privado de todo o conjunto de interações não verbais comuns nos cursos presenciais. Isto pode dificultar o desenvolver de processos de cooperação, competição, ajuda e outros que ocorrem com frequência nos ambientes presenciais. Tais fatores não são necessariamente ruins ou bons e há ainda um vasto campo de pesquisa comparativa a ser trilhado.

A emergência de questões deste tipo levou a autora a questionar a sua definição operacional inicial de que o "silêncio virtual" seria detectado apenas pela ausência de mensagens postadas no Facebook. Muitas interações estariam ocorrendo e que não seria adequado rotulá-las como "silêncio". O silêncio de um aluno presencial que está tentando raciocinar e que é finalizado com a elaboração de uma resposta correta e completa tem que ser considerado produtivo. Os "logs" do sistema de informática, obviamente, não podem comprovar explicitamente as interações do participante consigo mesmo, ou seja, as "reflexivas". Há que distinguir as "pausas" em uma conversação do que será caracterizado como "silêncio". 
Os resultados até agora encontrados sugerem que o termo silêncio virtual merece uma abordagem mais ampla, não podendo ficar adstrito ao entendimento de simples ato de não postar mensagens no ambiente virtual.

Há indícios de que a interação havida entre as partes foi maximizada pela atuação do Coordenador de Atividades, o qual utilizou dinâmica que primou pela otimização das interações, permitindo gradativo aumento no índice de interações, em cada ciclo do curso, diminuindo assim o silêncio.

As considerações tecidas levaram os pesquisadores a sugerir que se tente, em futuras análises, usar um contraste também com o termo "mutismo" e a estabelecer mais nuance para uma definição operacional do fenômeno pesquisado.

\section{REFERÊNCIAS}

BRASIL. Decreto 5622 de 19 de dezembro de 2005. Disponível em http://www.planalto.gov.br/ccivil 03/_ato2004-2006/2005/decreto/d5622.htm

GONÇALVES, Maria Ilse Rodrigues. Reflexões sobre 'silêncio virtual' no contexto do grupo de discussão na aprendizagem via rede. Revista Gestão Universitária, [s.1.], 2004. Disponível em http://www.gestaouniversitaria.com.br/artigos/reflexoes-sobre-silenciovirtual-no-contexto-do-grupo-de-discussao-na-aprendizagem-via-rede.

KENSKI, V. M. Educação e tecnologias: o novo ritmo da informação. Campinas, SP: Papirus, 2007.

LEÃO, Christiane Louise. Aspectos interacionais nos ambientes digitais de uma disciplina a distância do Posling - Cefet MG. Dissertação (Mestrado em Estudos de Linguagens) - CEFET, Belo Horizonte, 2014.

MATTAR, João. Tutoria e interação em educação a distância. São Paulo: Cengage Learning, 2012.

MINAYO, Maria Cecília de Souza. Ciência, técnica e arte: o desafio da pesquisa social. In: DESLANDE, Suely Ferreira; MINAYO, Maria Cecília de Souza (Org.). Pesquisa social: teoria, método e criatividade. Petrópolis: Vozes, 2001.

MOORE, Michael G. Teoria da distância transacional. Trad. Wilson Azevedo. Revista Brasileira de Aprendizagem Aberta e a Distancia, São Paulo, ago. 2002.

MORAN, José Manuel. Contribuições para uma pedagogia online. In: SILVA, Marcos (Org.). Educação online. 4. ed. São Paulo: Loyola, 2012

OLIVEIRA, Maria Marly de. Como fazer pesquisa qualitativa. 3. Ed. rev. Petrópolis: Vozes, 2010. 
PARREIRAS, Vicente Aguimar. Estratégias de aprendizagem on-line e autonomia: uma relação biunívoca ou antagônica? In: PAIVA, Vera Lúcia Menezes de Oliveira e (Org.). Interação e aprendizagem em ambiente virtual. 2. Ed. Belo Horizonte: Editora UFMG, 2010

SANTAELLA, L. Comunicação ubíqua: repercussões na cultura e educação. São Paulo: Paulus, 2013.

SILVA, Adelina. Da aula convencional para a aula invertida ferramentas digitais para a aula de hoje. In: Academinal.Edu. Disponível em https://www.academia.edu/13591362/Da_aula_convencional_para_a aula invertida_ferr amentas.

VALENTE, Armando. Blended learning e as mudanças no ensino superior: a proposta da sala de aula invertida. In Educar em Revista, Curitiba, Brasil, Edição Especial n. 4/2014, p. 79-97. Editora UFPR. Disponível em http://www.scielo.br/pdf/er/nspe4/0101-4358-eresp-04-00079.pdf

VIGOTSKY, L. S. A construção do pensamento e da linguagem. 2. Ed. São Paulo: Martins Fontes, 2009.

\section{OS AUTORES}

Heitor Garcia de Carvalho: Graduação em Pedagogia pela Universidade Federal de São João Del-Rei (1968); Mestrado em Educação, UFMG (1982); PhD Educational Technology - Concordia University - Montreal, Canadá (1987); MBA Gestão Tecnologia da Informação, Fundação Getúlio Vargas (2004); Pós-doutorado em Políticas de Ensino Superior na Faculdade de Psicologia e Ciências da Informação na Universidade do Porto, Portugal (2008); Professor CEFET-MG.

Josefa Aparecida da Silva Souza: Bacharelado em Direito, UFMG (1985/1990); Pósgraduação "Lato Sensu" em Direito Educacional, Faculdade São Luiz - MA (2005/2006); Pós-graduação "Lato Sensu" em Direito Civil /Processo Civil, Centro Universitário Newton Paiva (2010/2011); Especialista em Tecnologias da Educação, SENAC-MG (2011/2013); Mestrado em Estudos de Linguagens, CEFET-MG (2013/2015); Tutora EaD (Capacitação para Oficiais de Justiça do Tribunal de Justiça de Minas Gerais). 